\title{
Surgical Management of Toxic Multinodular Goiter
}

\author{
${ }^{1}$ Antoine Digonnet, ${ }^{1}$ Esther Willemse, ${ }^{1}$ Cécile Dekeyser, ${ }^{2}$ Nicolas de Saint Aubain \\ ${ }^{3}$ Moreau Michel, ${ }^{1}$ Guy Andry \\ ${ }^{1}$ Department of Head and Neck and Thoracic Surgery, Free University of Brussels, Jules Bordet Institute, Brussels, Belgium \\ ${ }^{2}$ Department of Pathology, Free University of Brussels, Jules Bordet Institute, Brussels, Belgium \\ ${ }^{3}$ Department of Biostatistics, Free University of Brussels, Jules Bordet Institute, Brussels, Belgium
}

Correspondence: Antoine Digonnet, Department of Head and Neck and Thoracic Surgery, Free University of Brussels Jules Bordet Institute, Rue Heger Bordet-1, 1000 Brussels, Belgium, Phone: 3225413319, Fax: 3225413141 e-mail: antoine.digonnet@ bordet.be

\section{ABSTRACT}

Management of toxic multinodular goiter (TMNG) is still debated. We report our current experience with thyroidectomy for toxic multinodular goiter at a tertiary center. A retrospective database of 141 patients who underwent surgery for TMNG disease from January 1985 to December 2008. During that period, six patients underwent subtotal thyroidectomy and 135 patients underwent near total thyroidectomy. Around 53 patients (38\%) underwent surgery for recurrent disease after medical therapy; 88 patients (62\%) had surgery as a primary treatment, the indications were large goiter size in $58(66 \%)$, associated cold nodule in $16(18 \%)$, patient preference in $14(16 \%)$. The incidence of cancer was $6.4 \%$. Permanent hypoparathyroidism was observed in two patients. Unilateral transitory vocal cord palsy was observed in 11 patients (8\%), no bilateral transitory vocal cord palsy was observed. One unilateral definitive vocal cord palsy was observed and was provoked by a mediastinal compression. Two patients (1.5\%) experienced postoperative hemorrhagia requiring surgical revision. Near total thyroidectomy for TMNG provide an immediate and definitive treatment with a low complication rate. Near total thyroidectomy offers an appropriate treatment for coexisting malignancy. Only NTT can alleviate compressive symptoms. This procedure can be safely recommended even as a primary treatment.

Keywords: Thyroidectomy, Toxic multinodular goiter, Plummer's disease.

\section{INTRODUCTION}

Toxic multinodular goiter (TMNG) is a thyroid enlargement which contains at least two autonomously functioning nodules producing excessive amounts of thyroid hormones. It is the commonest cause of hyperthyroidism in the elderly. ${ }^{1}$ TMNG is a slow-developing process with multiple nodules, some of which become autonomous and may evolve to cause thyrotoxicoisis. In Graves' disease, near-total thyroidectomy (NTT) is usually the preferred therapeutic option, ${ }^{2,3}$ but optimal treatment for TMNG is controversial. Whether subtotal thyroidectomy (STT) is more suitable for TMNG or NTT is also controversial.

There are two standard treatments for TMNG: Radioiodine therapy (RAI) and thyroidectomy. Antithyroid drugs are rarely successful in the long-term. Percutaneous ultrasound-guided ethanol injection of toxic nodules can be useful if surgery is contraindicated. ${ }^{2}$ Thyroidectomy may offer definitive treatment of the disorder, but patients will be subjected to the risk of surgery as well as the possible complications of recurrent nerve injury and hypocalcemia.

The aim of the present study was to assess the surgical management of TMNG in terms of safety and efficacy.

\section{MATERIALS AND METHODS}

In this retrospective study, data were collected from patients with TMNG consecutively treated by surgery at our institution from January 1985 to December 2007. All patients were referred with a prior diagnosis of TMNG determined by clinical presentation, laboratory testing, and radiographic imaging (including ultrasound (US) and isotopic scanning). Patients treated before 1986 had subtotal thyroidectomy (STT). Patients treated after 1986 underwent NTT.

In patients who underwent NTT, the size of the thyroid remnant was intended to be as narrow as possible with respect to the laryngeal nerves; we always left $<0.5 \mathrm{gm}$. For those who underwent STT, the size of the thyroid remnant was 2 to $4 \mathrm{gm}$. This practice was based on a "rule of thumb" approach and was aimed at leaving sufficient tissue near the superior pedicle of the gland and around the ligament of Berry to avoid the need for subsequent oral hormonal supplementation.

The indications for surgery were: recurrence of hyperthyroidism after failed medical treatment; an associated cold nodule; goiter sizes with clinically relevant signs (compromising of the airways or swallowing); or patient preference.

Preoperative evaluation involved thyroid blood test, US, and fiberoptic laryngoscopy. If US showed nodules with a diameter $>10 \mathrm{~mm}$ or suspicious features (calcification, irregular contours), the patient underwent fine-needle aspiration cytology (FNAC) of the thyroid gland during the procedure. Patients were also evaluated with a questionnaire assessing hyperthyroid symptoms, such as weight loss, thermophobia, hand trembling, 
tachycardia (heart rate $>100$ beats per minute), diarrhea, insomnia. Preoperatively, all patients were made euthyroid by the use of antithyroid drugs, and lugol solution (equimolar potassium iodine and metallic iodine) was added for the last eight days before surgery to decrease thyroid blood flow. ${ }^{3}$

Intraoperatively, an attempt was made to preserve all the parathyroid glands in situ but, if resected, they were transplanted and fragmented into a pouch of the sternocleidomastoid muscle. The recurrent nerves were systematically identified using the technique described by Lahey ${ }^{4}$ from the upper mediastinum to the cricothyroid muscle. All patients were drained using a vacuum 8 gauge polyvinyl chloride (PVC). Immediate postoperative evaluation involved the serum level of parathyroid hormone (PTH), serum calcium and inorganic phosphorus on day 0 (4-6 hours after the procedure) and on day 2 (evaluation was repeated if values were outside the normal range). Fiberoptic laryngoscopy was undertaken by an ear, nose and throat (ENT) specialist 1 week after surgery to evaluate laryngeal function.

We recorded the following complications: bleeding requiring repeat surgery; paresia or palsy of the vocal cords, hypoparathyroidism, wound infection and other systemic complications. Hypoparathyroidism was defined as the need for calcium supplementation to reach the normal level of calcium in serum $(2.2 \mathrm{mmol} / \mathrm{L})$ and a low serum level of PTH $(<15 \mathrm{pg} / \mathrm{mL})$. Blood samples for PTH testing were taken 4 to 8 hours after the procedure and repeated at 48 hours and 1 week. The length of hypoparathyroidism was arbitrarily divided into four periods: $>1$ week, $>1$ month, 6 to 12 months and permanent.

Patients were re-evaluated at 1 week, 1 month, 2 months, 6 months, 12 months and once a year after surgery. This followup involved physical examination, thyroid blood test and serum PTH (if necessary).

\section{RESULTS}

A total of 141 patients [122 females (86.5\%) and 19 males (13.5\%)] underwent thyroidectomy for TMNG between 1985 and 2007 at our institution. The mean age was 49 (range, 9-84 years). Before 1986, six patients underwent SST. Since 1986, NTT was undertaken in 135 patients. The mean weight of specimens was $82 \mathrm{gm}$ (range, 18-398 gm).

About 53 patients (38\%) underwent surgery for recurrent disease after medical therapy (radioiodine treatment and/or antithyroid drugs); 88 patients $(62 \%)$ had surgery as the primary treatment after preoperative antithyroid drug treatment to make the patient euthyroid. Of these 88 patients, the indications were large goiter in 58 (66\%) [mean weight, 147 gm (range, 70-398 gm), an associated cold nodule in $16(18 \%)$ and patient preference in $14(16 \%)]$.

Of the 141 patients, there was a history of thermophobia in 48 (34\%); weight loss in $40(28 \%)$; tachycardia in $35(25 \%)$; hand trembling in $21(15 \%)$ and diarrhea in six patients (4\%).

About 100 patients (144 nodules) underwent FNAC of the thyroid gland. This procedure demonstrated colloid tissues in
30 patients (51 nodules); normal follicular cells in 35 patients (43 nodules); and a suspicion of neoplasia in six patients (6 nodules). Among the latter, only two patients had confirmed malignancy at definitive histology (one papillar and one follicular carcinoma). The cytologic sample could not be interpreted in 29 patients (44 nodules).

During the surgical procedure, the number of parathyroid glands preserved was: four in 62 patients $(44 \%)$, three in $50(35.5 \%)$, two in $16(11,5 \%)$ and one in $13(9 \%)$. Ten and two patients had one and two parathyroid glands respectively, transplanted into the sternocleidomastoid muscle.

Histological findings confirmed the diagnosis of TMNG in 139 patients $(98.5 \%)$ and demonstrated thyroiditis in two patients $(1.5 \%)$.

Coincidental malignancy was also found in nine patients $(6.4 \%)$. There were seven papillary carcinomas and two follicular carcinomas (mean size, $0.6 \mathrm{~cm}$; range, $0.1-1.3 \mathrm{~cm}$ ).

The mean hospital stay was 6 days, including the day before surgery (range, 31 days) for the period studied but, after year 2000, the mean hospital stay was 4.2 days (range, 2-42 days) with a median stay of 2 days.

The mean duration of follow-up was 62 months (range, 2-233 months). We achieved a follow-up of $>60$ months in 55 patients, and a follow-up of $>120$ months in 27 patients.

Two patients (1.5\%) experienced postoperative hemorrhagia requiring surgical revision, including one subject who required blood transfusion. The latter was given heparin for atrial fibrillation a few days before surgery. Bleeding appeared 48 hours after surgery and was provoked by a HIT (heparininduced thrombocytopenia) syndrome. This was complicated by a lung infection and a pulmonary embolism. This patient was discharged 42 days after surgery and is doing well 3 years after surgery. The recovery of the other patient was uneventful, and he was discharged on the eighth postoperative day.

Three patients (2\%) had wound infections which resolved with local wound care. Around 11 patients $(8 \%)$ experienced unilateral paresia of the vocal cords. All of these subjects fully recovered within 2 months. Laryngoscopic examination showed normal and symmetric mobility of both vocal cords; all of these patients reported normal speech phonation. One patient experienced a definitive unilateral paralysis of the vocal cord. This paralysis was found to be present before thyroidectomy and provoked by mediastinal adenopathy of non-small-cell lung carcinoma. The surgical indication was based on uncontrollable hyperthyroidism. Bilateral paresia of the vocal cords was not observed.

Immediately after surgery, 90 patients $(64 \%)$ did not have hypoparathyroidism; the mean concentration of PTH in serum was $22 \mathrm{pg} / \mathrm{mL}$ (range, $11-37 \mathrm{pg} / \mathrm{mL}$ ). Thirty-five patients (25\%) had hypoparathyroidism after $>1$ week. Seven patients $(5 \%)$ had hypoparathyroidism between 1 and 6 months. Seven patients (5\%) had hypoparathyroidism between 6 and 12 months. Two patients (1\%) experienced definitive hypoparathyroidism; these two patients had three parathyroid glands preserved in situ. Both of these patients required oral supplementation of calcium, but 
still had a recordable level of PTH (13 pg/mL). Table 1 summarizes the postoperative PTH level in each group.

Among those who experienced hypoparathyroidism for $>1$ month, eight subjects had four parathyroid glands preserved in situ, three patients had two glands preserved in situ, and one patient had one gland preserved in situ. Among these patients, only one patient had hypoparathyroidism for $>6$ months.

Among the six patients who underwent bilateral STT, one recurrence of hyperthyroidism was observed. It was a benign recurrence that was managed by suppression of oral hormonotherapy. No reoccurrences were observed in the 135 patients who underwent NTT.

All the patients were classified as stable euthyroid within 12 months and 125 patients (89\%) within 3 months. During follow-up, seven late deaths were observed but none were attributable to the procedure (four cases of lung cancer, one renal cancer, one breast cancer, one elderly).

\section{DISCUSSION}

The management of TMNG is controversial. Furthermore, some studies have confused Graves' disease with TMNG. ${ }^{5}$ Antithyroid therapy is ineffective in the long-term with $95 \%$ of patients having a relapse at 2 years. ${ }^{6}$ Percutaneous ethanol ablation is the third-line treatment for TMNG and could be adjuvant therapy to RAI therapy. ${ }^{2}$

It can take several months before the full radiation dose effect of RAI therapy is noticed. ${ }^{6}$ RAI can also lead to unpredictable effects because of the conflict between administering a dose that is sufficiently high to avoid recurrence of thyrotoxicosis and the risk of causing permanent hypothyroidism. The overall risk of persistent (or recurrent) thyrotoxicosis is estimated to be 5 to $25 \%$ and that of developing hypothyroidism is $20 \%$ in the first year after RAI therapy, with a subsequent increase of $3 \%$ per year. ${ }^{6}$

Moreover, even if RAI cures hyperthyroidism, it does not alleviate compressive symptoms in large goiters. $\mathrm{Kang}^{7}$ stated that a large $(>100 \mathrm{gm})$ TMNG invariably persists after RAI therapy.

Hamburger $^{8}$ successfully managed 26 of 35 patients who all had a large ( $>100 \mathrm{gm}$ ) TMNG. However, the volume of the goiter persisted in $89 \%$ of patients without any relief from compressive symptoms. In our series, 58 patients (41\%)

Table 1: PTH levels in the postoperative period

\begin{tabular}{|c|c|c|c|}
\hline & \multicolumn{3}{|c|}{ Duration of hypoparathyroidism } \\
\hline & $\begin{array}{l}>1 \text { week } \\
n=35\end{array}$ & $\begin{array}{l}1-6 \text { months } \\
n=7\end{array}$ & $\begin{array}{l}>6 \text { months } \\
n=7\end{array}$ \\
\hline $\begin{array}{l}\text { Postoperative } \\
\text { PTH }\end{array}$ & $\begin{array}{l}8.1 \mathrm{pg} / \mathrm{mL} \\
\text { (range, 3-16) }\end{array}$ & $\begin{array}{l}7.2 \mathrm{pg} / \mathrm{mL} \\
\text { (range, 3-11) }\end{array}$ & $\begin{array}{l}6.05 \mathrm{pg} / \mathrm{mL} \\
\text { (range, } 0-7 \text { ) }\end{array}$ \\
\hline $\begin{array}{l}\text { First normal } \\
\text { PTH }\end{array}$ & $\begin{array}{l}25.4 \mathrm{pg} / \mathrm{mL} \\
\text { (range, } 16-67 \text { ) }\end{array}$ & $\begin{array}{l}26.75 \mathrm{pg} / \mathrm{mL} \\
\text { (range, 20-42) }\end{array}$ & $\begin{array}{l}25.25 \mathrm{pg} / \mathrm{mL} \\
\text { (range, 14-44) }\end{array}$ \\
\hline
\end{tabular}

were symptomatic with a large goiter size [mean, 147 gm (range, 70-398 gm)].

Furthermore, many patients expressed relief of compression after surgery that they may have not appreciated preoperatively. A recent study $^{2}$ reported that, despite documentation of compressive symptoms, $<20 \%$ of patients expressed feelings of compression. This emphasizes the fact that a larger number of patients than suggested by preoperative evaluation could be relieved of compressive symptoms.

In comparison with Graves' disease, TMNG requires a higher dose to be effective because of the lower iodine uptake and its nonhomogeneity in patients with Plummer's disease. ${ }^{9-17}$

Surgery provides immediate treatment of thyrotoxicosis whereas RAI therapy takes longer. In our series, rapid control of thyrotoxicosis was achieved in all cases, and 125 patients $(89 \%)$ were classified as stable euthyroid within 3 months. Among the 55 patients who have been followed up for $>5$ years, all are classified as stable euthyroid with a single daily oral intake of thyroid hormone. At this time, there is no worsening or improvement of orbithopathy. About 27 patients had recordable data for $>120$ months. Among the 27 patients, only five patients had modification of their hormonal doses between 5 years and 10 years. After 10 years, a change in orbithopathy was not observed.

The present study showed that surgery provides immediate and definitive treatment with a low prevalence of complications. Only one recurrence was observed, and occurred after STT; no recurrence was observed among the 135 patients undergoing NTT. STT leaves behind posterior nodules (Zuckerkandl's tubercle), which may account for a substantial prevalence of recurrence and persistence of compressive symptoms. ${ }^{10}$

Furthermore, the only recurrence in the present study was managed with suppression of oral hormone therapy. Transient palsy of the vocal cord was experienced postoperatively in $8 \%$ of patients, but was reversible within 2 months in all cases. Hypoparathyroidism lasting $<1$ month was seen in $25 \%$ of all patients. Only $10 \%$ of patients had more prolonged hypoparathyroidism (1-12 months). Only two patients had definitive hypoparathyroidism.

Few studies have ascertained the role of NTT in TMNG. Table 2 summarizes the relevant information on the surgical approach in TMNG in recent studies. ${ }^{11,12}$ A retrospective study ${ }^{7}$ from the Mayo Clinic (Rochester, MN, USA) dealing with 104 cases of TMNG demonstrated control of thyrotoxicosis in $96 \%$ of patients within 1 month. In this study, 76 patients underwent NTT or total thyroidectomy (TT), the authors did not precise which procedure had the $4 \%$ without a control of hyperthyroidism. In their study, paralysis of the recurrent laryngeal nerve and definitive hypoparathyroidism, each occurred in $2 \%$ of patients. In the present study, we achieved control of thyrotoxicosis in all cases; only two patients experienced definitive hypoparathyroidism, and permanent paralysis of the recurrent laryngeal nerve was not linked with the procedure. 
Table 2: Studies on the surgical approach for TMNG

\begin{tabular}{|c|c|c|c|c|c|c|c|c|}
\hline Authors & $\begin{array}{l}\text { Duration and } \\
\text { type of study }\end{array}$ & $\begin{array}{l}\text { Number of } \\
\text { patients }\end{array}$ & $\begin{array}{l}\text { Permanent } \\
\text { palsy of the } \\
\text { RLN (\%) }\end{array}$ & $\begin{array}{c}\text { Permanent } \\
\text { hypoparathyroidism } \\
\text { (\%) }\end{array}$ & $\begin{array}{l}\text { Temporary palsy } \\
\text { of the RLN (\%) }\end{array}$ & $\begin{array}{c}\text { Temporary } \\
\text { hypocalcemia } \\
\text { (\%) }\end{array}$ & $\begin{array}{c}\text { Neck } \\
\text { hematoma } \\
\text { (\%) }\end{array}$ & $\begin{array}{c}\text { Wound } \\
\text { infection } \\
\text { (\%) }\end{array}$ \\
\hline $\begin{array}{l}\mathrm{Kang}^{7} \\
\text { et al }\end{array}$ & $\begin{array}{c}1990-1999 \\
\text { retrospective }\end{array}$ & $\begin{array}{l}76 \text { NTT } \\
46 \text { STT }\end{array}$ & $\begin{array}{l}2 \\
\text { UK }\end{array}$ & $\begin{array}{l}2 \\
\text { UK }\end{array}$ & $\begin{array}{l}\text { UK } \\
\text { UK }\end{array}$ & $\begin{array}{l}\text { UK } \\
\text { UK }\end{array}$ & $\begin{array}{l}0.5 \\
\text { UK }\end{array}$ & $\begin{array}{l}0.5 \\
\text { UK }\end{array}$ \\
\hline $\begin{array}{l}\text { Rios }^{11} \\
\text { et al }\end{array}$ & $\begin{array}{c}1970-1999 \\
\text { retrospective }\end{array}$ & $\begin{array}{l}102 \text { NTT } \\
3 \text { STT }\end{array}$ & 3.6 & 3.6 & 18 & 16 & 2.7 & UK \\
\hline $\begin{array}{l}\text { Alimoglu }{ }^{12} \\
\text { et al }\end{array}$ & $\begin{array}{c}2000-2003 \\
\text { retrospective }\end{array}$ & $\begin{array}{l}65 \text { NTT } \\
35 \text { STT }\end{array}$ & $\begin{array}{c}1.5 \\
0\end{array}$ & $\begin{array}{l}3 \\
0\end{array}$ & $\begin{array}{c}4.6 \\
2.85\end{array}$ & $\begin{array}{c}20 \\
14.28\end{array}$ & $\begin{array}{l}3 \\
0\end{array}$ & $\begin{array}{l}0 \\
0\end{array}$ \\
\hline $\begin{array}{l}\text { Porterfield } \\
\text { et al }\end{array}$ & $\begin{array}{l}2000-2006 \\
\text { retrospective }\end{array}$ & $\begin{array}{l}146 \text { NTT } \\
79 \text { STT }\end{array}$ & 0 & 1.5 & 2.2 & UK & UK & UK \\
\hline $\begin{array}{l}\text { Hussain }{ }^{5} \\
\text { et al }\end{array}$ & $\begin{array}{c}2003-2005 \\
\text { retrospective }\end{array}$ & $\begin{array}{l}67 \mathrm{TT} \\
0 \mathrm{STT}\end{array}$ & 0 & 1.5 & 1.5 & 26.6 & 0 & 1.5 \\
\hline
\end{tabular}

Alimoglu et al ${ }^{11}$ observed among 100 patients with TMNG, the outcomes of 65 patients who underwent NTT or TT and of 35 patients who underwent STT. The prevalence of complications was similar in both groups, but four patients (11\%) in the STT group experienced persistent hyperthyroidism whereas all the patients in the NTT or TT group had hypothyroidism after surgery. We believe that postoperative hypothyroidism is a goal to reach rather than a complication. From this goal, euthyroidism can be easily restored with oral substitution. Another study leads to the same conclusion; ${ }^{13}$ among 580 patients who underwent NTT/TT and 170 patients who underwent STT for benign multinodular goiter, the authors found a comparable prevalence of complications except for hypoparathyroidism. Indeed, 78 patients (30\%) in the TT group experienced temporary hypoparathyroidism whereas only 14 patients $(8.2 \%)$ experienced temporary hypoparathyroidism in the STT group. In the present study, 51 patients $(36 \%)$ had temporary hypoparathyroidism (including 35 patients who returned to normal parathyroid function within 1 month). Delbridge et al ${ }^{14}$ stated that transient hypoparathyroidism should be an accepted outcome of thyroid surgery rather than a complication. We would add that it is an acceptable outcome only if the hypoparathyroidism is reversible. This was the case in our study, only two patients (1.4\%) experienced definitive hypoparathyroidism with a recordable PTH (13 pg/mL).

It was previously thought that hyperthyroidism protects against thyroid carcinomas, and the risk of thyroid cancer was reported to be low as $2 \%,{ }^{14}$ whereas the frequency of carcinoma in TMNG was reported to be $<1 \% .^{15,16}$ In our series, thyroid malignancy was found in $6.4 \%$ of patients, and recent studies ${ }^{17,18}$ reported a prevalence of carcinomas in TMNG of 6.5 to $9 \%$. We believe that the increased prevalence of cancer in TMNG in recent years could be attributed to better detection of nodules (US, FNAC) and the number of histological sections examined per specimen. In the present study, the two carcinomas $>10 \mathrm{~mm}$ were revealed by FNAC.

The present study confirmed that the frequency of detecting neoplasia incidentally for patients undergoing surgery for
TMNG is not negligible. These patients would not have received appropriate treatment if they had been treated only by RAI or antithyroid drugs.

\section{CONCLUSION}

Surgical complications, such as paralysis of the vocal cords, permanent hypoparathyroidism and cervical hematoma are uncommon in this series. STT for Plummer's disease leaves hypersecreting thyroid tissue behind, and should not be used.

NTT for TMNG provides immediate and definitive treatment and is associated with a low prevalence of complications rate. NTT offers appropriate treatment for coexisting malignancy. Only NTT can alleviate compressive symptoms. Since RAI therapy can have various side effects, NTT can be safely recommended as primary treatment.

\section{ACKNOWLEDGMENT}

This work was undertaken, thanks to ground support of "les amis de l' institut Bordet."

\section{REFERENCES}

1. Vitti P, Rago T, Tonacchera M, et al. Toxic multinodular goiter in the elderly. J Endocrinol Invest 2002;25(10 Suppl):16-18.

2. Porterfield JR Jr, Thompson GB, Farley DR, et al. Evidencebased management of toxic multinodular goiter (Plummer's Disease). World J Surg 2008;32(7):1278-84

3. Erbil Y, Ozluk Y, Giriş M, et al. Effect of lugol solution on thyroid gland blood flow and microvessel density in the patients with Graves' disease. Clin Endocrinol Metab 2007;92(6): 2182-89 (Epub 2007 Mar 27).

4. Lahey FH. Technique of subtotal thyroidectomy. Surg Clin North Am 1949;29(3):641-58.

5. Hussain M, Hisham AN. Total thyroidectomy: The procedure of choice for toxic goitre. Asian J Surg Apr 2008;31(2):59-62.

6. Weetman AP. Graves' disease. N Engl J Med 2000;343(17): 1236-48.

7. Kang AS, Grant CS, Thompson GB, et al. Current treatment of nodular goiter with hyperthyroidism (Plummer's disease): Surgery versus radioiodine. Surgery 2002;132(6):916-23; discussion 923. 
8. Hamburger JI, Hamburger SW. Diagnosis and management of large toxic multinodular goiters. J Nucl Med 1985;26(8): 888-92.

9. Jensen MD, Gharib H, Naessens JM, et al. Treatment of toxic multinodular goiter (Plummer's disease): Surgery or radioiodine? World J Surg 1986;10(4):673-80.

10. Pelizzo MR, Toniato A, Gemo GJ. Zuckerkandl's tuberculum: An arrow pointing to the recurrent laryngeal nerve (constant anatomical landmark). Am Coll Surg 1988;187(3):333-36.

11. Alimoglu O, Akdag M, Sahin M, et al. Comparison of surgical techniques for treatment of benign toxic multinodular goiter. World J Surg July 2005;29(7):921-24.

12. Ríos A, Rodríguez JM, Balsalobre MD, et al. Results of surgery for toxic multinodular goiter. Surg Today 2005;35(11):901-06.

13. Ozbas S, Kocak S, Aydintug S, et al. Comparison of the complications of subtotal, near total and total thyroidectomy in the surgical management of multinodular goitre. Endocr J 2005;52(2):199-205.

14. Delbridge L, Guinea AI, Reeve TS. Total thyroidectomy for bilateral benign multinodular goiter: Effect of changing practice. Arch Surg 1999;134(12):1389-93.

15. Gittoes NJ, Franklyn JA. Hyperthyroidism, current treatment guidelines. Drugs 1998;55(4):543-53.

16. Vaiana R, Cappelli C, Perini P, et al. Hyperthyroidism and concurrent thyroid cancer. Tumori 1999;85(4):247-52.

17. Senyurek Giles Y, Tunca F, Boztepe H, et al. The risk factors for malignancy in surgically treated patients for Graves' disease, toxic multinodular goiter, and toxic adenoma. Surgery 2008;144(6):1028-36; discussion 1036-37.

18. Cerci C, Cerci SS, Eroglu E, et al. Thyroid cancer in toxic and non-toxic multinodular goiter. Postgrad Med 2007;53(3): 157-60. 